\title{
Encephalopathy in renovascular hypertension associated with the use of oral contraceptives
}

\author{
John R. Bradley, John Reynolds, Paul F. Williams and Derek S. Appleton
}

Addenbrooke's Hospital, Hills Road, Cambridge CB2 2QQ, UK.

\begin{abstract}
Summary: Two female patients aged 19 years and 27 years presented with hypertensive encephalopathy and were subsequently found to have renal artery stenosis due to fibromuscular dysplasia. Both patients had had normal blood pressures recorded within the previous 6 months whilst taking the oral contraceptive pill. Their neurological state returned to normal with hypertensive control and in one case the hypertension was cured by dilatation of the renal artery stenosis by balloon angioplasty.
\end{abstract}

\section{Introduction}

Renal artery stenosis due to fibromuscular dysplasia is an important cause of hypertension in young women. Although controversy has existed regarding the natural history of this condition (Simon et al., 1972) it is now generally accepted that a shorter duration of hypertension suggests a renovascular cause (Vaughan et al., 1984). We describe two patients with renal artery stenosis who presented with hypertensive encephalopathy, normal blood pressures having been recorded within the previous 6 months whilst taking oral contraceptives.

\section{Case reports}

\section{Case 1}

A 27 year old woman was admitted to hospital following two grand mal fits. She had suffered from increasing headaches, nausea and vomiting over the previous month. Her blood pressure had been elevated at $160 / 110 \mathrm{mmHg}$ one week before admission but had been normal over the previous 11 years whilst taking oral contraceptives (various formulations of combined oestrogen and progestogen) which she had stopped two months previously. She was a non-smoker. On admission she had a sinus tachycardia of 120 /minute and blood pressure of $210 / 110 \mathrm{mmHg}$. There was bilateral papilloedema but no localizing neurological abnormality. Haemoglobin was $17.3 \mathrm{~g} / \mathrm{dl}$ and white cell count $16.8 \times 10^{9} / 1$. Blood urea was $7.1 \mathrm{mmol} / \mathrm{l}$,

Correspondence: J.R. Bradley, B. Med. Sci., M.R.C.P.(UK), Renal Unit, Addenbrooke's Hospital, Hills Road, Cambridge CB2 2QQ

Accepted: 30 May 1986 creatinine $106 \mu \mathrm{mol} / \mathrm{l}$ and 24 hour urinary protein loss less than $0.2 \mathrm{~g}$. Chest X-ray and cranial computed tomography scan were normal and lumbar puncture revealed an elevated cerebrospinal fluid pressure of $330 \mathrm{~mm}$ but with normal protein content and microscopy. Her blood pressure was controlled with atenolol, nifedipine and bendrofluazide and her conscious level returned to normal with no further fits. An intravenous urogram revealed a small left kidney with a delayed nephrogram and subsequent arteriography showed bilateral medial fibromuscular dysplasia with a narrow stenosis of the left renal artery (Figure 1). Attempted balloon angioplasty was unsuccessful due to arterial spasm.

Four months after presentation she became pregnant. Blood pressure was controlled with methyl dopa during pregnancy which progressed uneventfully to full term.

\section{Case 2}

A 19 year old girl became confused and suffered a grand mal convulsion. She had complained of headaches over the previous 3 days. Her blood pressure had been normal over the previous 6 months whilst taking Logynon (phased formulation of ethinyloestradiol and levonorgestrel). She was a non-smoker. On admission to hospital she suffered further generalized convulsions. She had a sinus tachycardia of 120 /minute and blood pressure of $180 / 140 \mathrm{mmHg}$. Her fundi were normal and there were no focal neurological signs. Haemoglobin was $15.2 \mathrm{~g} / \mathrm{dl}$ and white cell count $19 \times 10^{9} / 1$. Blood urea was $5.3 \mathrm{mmol} / \mathrm{l}$ and creatinine $81 \mu \mathrm{mol} / 1$. Chest X-ray and cranial computed tomographic scan were normal and lumbar puncture revealed an elevated cerebrospinal fluid pressure of 


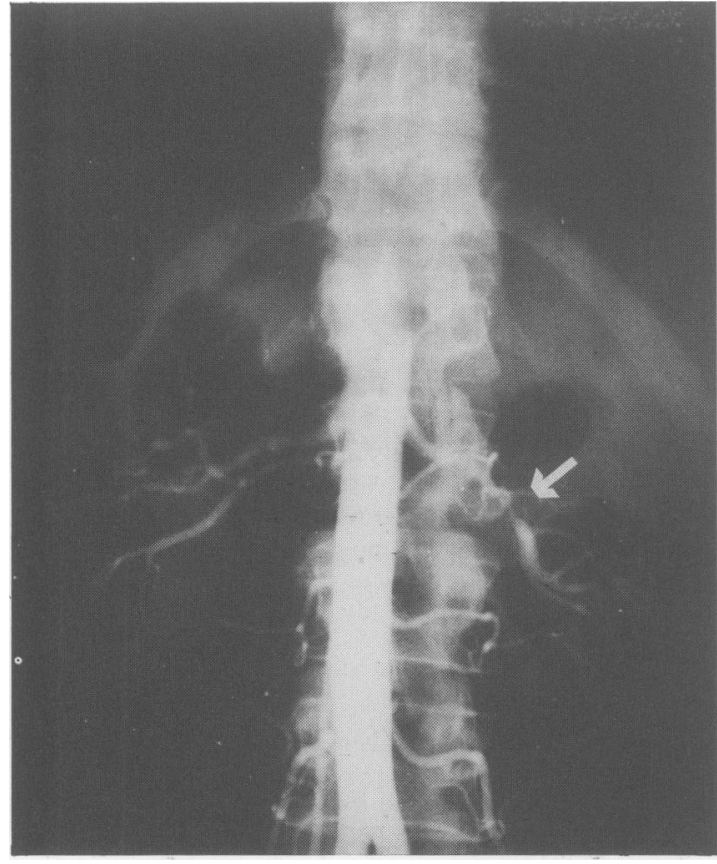

Figuré 1 Case 1. Renal arteriogram showing bilateral fibromuscular dysplasia with a narrow stenosis of the left renal artery (arrowed):

$300 \mathrm{~mm}$ but with normal constituents. Despite control of her convulsions with intravenous chlormethiazole her blood pressure rose to $220 / 140 \mathrm{mmHg}$ and this was controlled with intravenous hydralazine and propranolol. The following day she was conscious and was changed to oral therapy. A renogram and DMSA scan showed normal sized kidneys but there was evidence of decreased blood flow to the left kidney with an increased transit time. Renal arteriography showed a stenosis of the left renal artery, typical of intimal fibromuscular dysplasia (Figure 2), which was dilated by balloon angioplasty. Anti-hypertensive medication was withdrawn post-operatively and her blood pressure has remained well controlled.

\section{Discussion}

Several similarities exist between the two patients described. Although neither of the patients smoked cigarettes, a factor which has been associated with the development of both fibromuscular and atherosclerotic renal artery stenosis (Nicholson et al., 1983), and also malignant hypertension (Bloxham et al., 1979), both had been taking combined oestrogen and

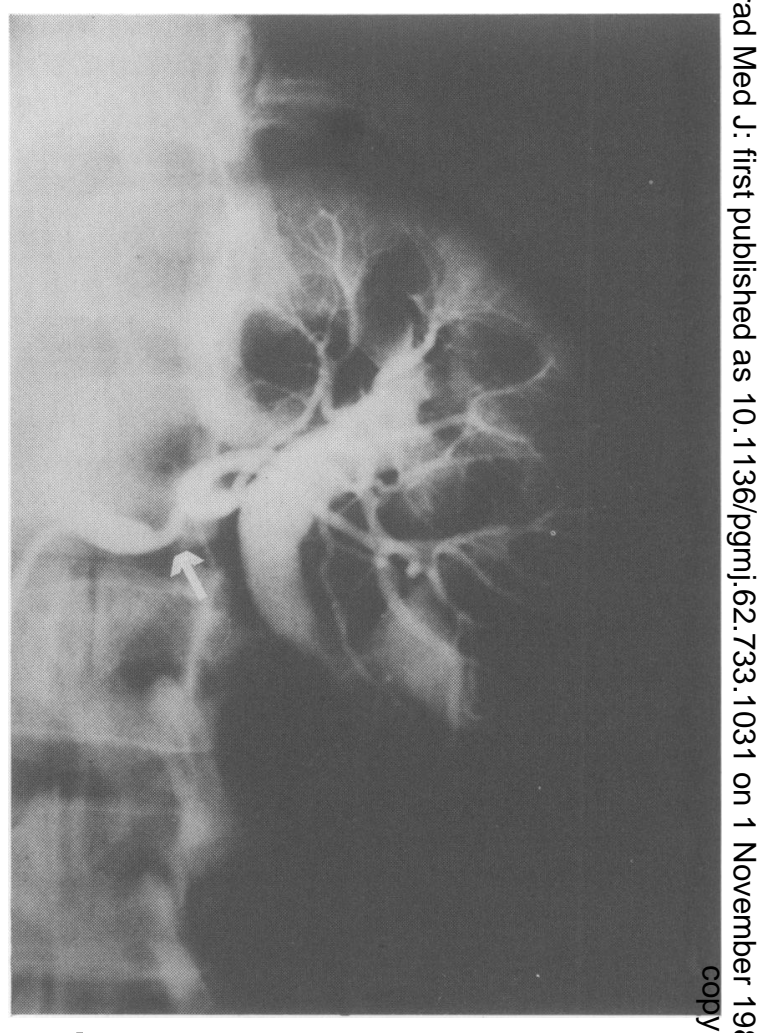

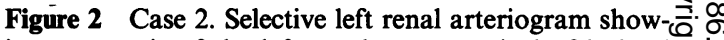
ing a stenosis of the left renal artery typical of intimal fibromuscular dysplasia (arrowed).

progestogen oral contraceptives. Oral contraceptives have been associated with a rise in blood pressure in normotensive women (Weir et al., 1974) and an accentuation of pre-existing hypertension (Woods, 1967). In addition an association between the development of malignant hypertension and oral contraceptive therapy in the absence of renovascular disease has been described (Dunn et al., 1975). Although renal artery thrombosis has been described in a young woman taking oral contraceptives (Golbus et al., 1979) we are unaware of any reports of an association between the use of oral contraceptives and the development of fibromuscular dysplasia.

In both of the cases described the onset of hypertension was rapid with encephalopathy being the presenting feature. Hypertensive encephalopathy is well recognized as a presenting feature of renal transplant $\mathrm{\omega}$ artery stenosis (Tejani, 1983; McGonigle et al., 1984) but not in cases of native renal artery stenosis. One of $\stackrel{Q}{C}$ the patients had actually stopped using oral contracep- $\mathbb{\infty}$ tives two months before presentation, suggesting that ? 
although there may have been an association between oral contraceptive use and the development of fibromuscular dysplasia it could not be implicated in the mode of presentation. Furthermore her blood pressure was controlled without problems during her ensuing pregnancy.

Patients presenting with hypertensive ence-

\section{References}

BLOXHAM, C.A., BEEVERS, D.G. \& WALKER, J.M. (1979). Malignant hypertension and cigarette smoking. British Medical Journal, 1, 581.

DUNN, F.G., JONES, J.V. \& FIFE, R. (1975). Malignant hypertension associated with use of oral contraceptives. British Heart Journal, 37, 336.

GOLBUS, S.M., SWERDLIN, A.R., MITAS, J.A., ROWLEY, W.R. \& JAMES, D.R. (1979). Renal artery thrombosis in a young woman taking oral contraceptives. Annals of Internal Medicine, 90, 939.

MCGONIGLE, R.J., BEWICK, M., TRAFFORD, J.A. \& PARSONS, V. (1984). Hypertensive encephalopathy complicating transplant renal artery stenosis. Postgraduate Medical Journal, 60, 356.

NICHOLSON, J.P., TEICHMAN, S.L., ALDERMAN, M.H., SOS, T.A., PICKERING, T.G. \& LARAGH, J.H. (1983). Cigarette smoking and renovascular hypertension. Lancet, ii, 765. phalopathy should be screened carefully for evidence of renal artery stenosis.

\section{Acknowledgements}

We wish to thank Dr D.B. Evans and Dr J.S. Pryor for permission to present these cases.

SIMON, N., FRANKLIN, S.S., BLEIFER, K.H. \& MAXWELL, M.H. (1972). Clinical characteristics of renovascular hypertension. Journal of the American Medical Association, 220, 1209.

TEJANI, A. (1983). Post transplant hypertension and hypertensive encephalopathy in renal allograft recipients. Nephron, 34, 73.

VAUGHAN, E.D., CASE, D.B., PICKERING, T.G., SOSA, R.E., SOS, T.A. \& LARAGH, J.H. (1984). Clinical evaluation of renovascular hypertension and therapeutic decisions. Urologic Clinics of North America, 11, 393.

WEIR, R.J., BRIGGS, E., MACK, A., NAISMITH, L., TAYLOR, L. \& WILSON, E. (1974). Blood pressure in women taking oral contraceptives. British Medical Journal, 1, 533.

WOODS, J.W. (1967). Oral contraceptives and hypertension. Lancet, ii, 653. 